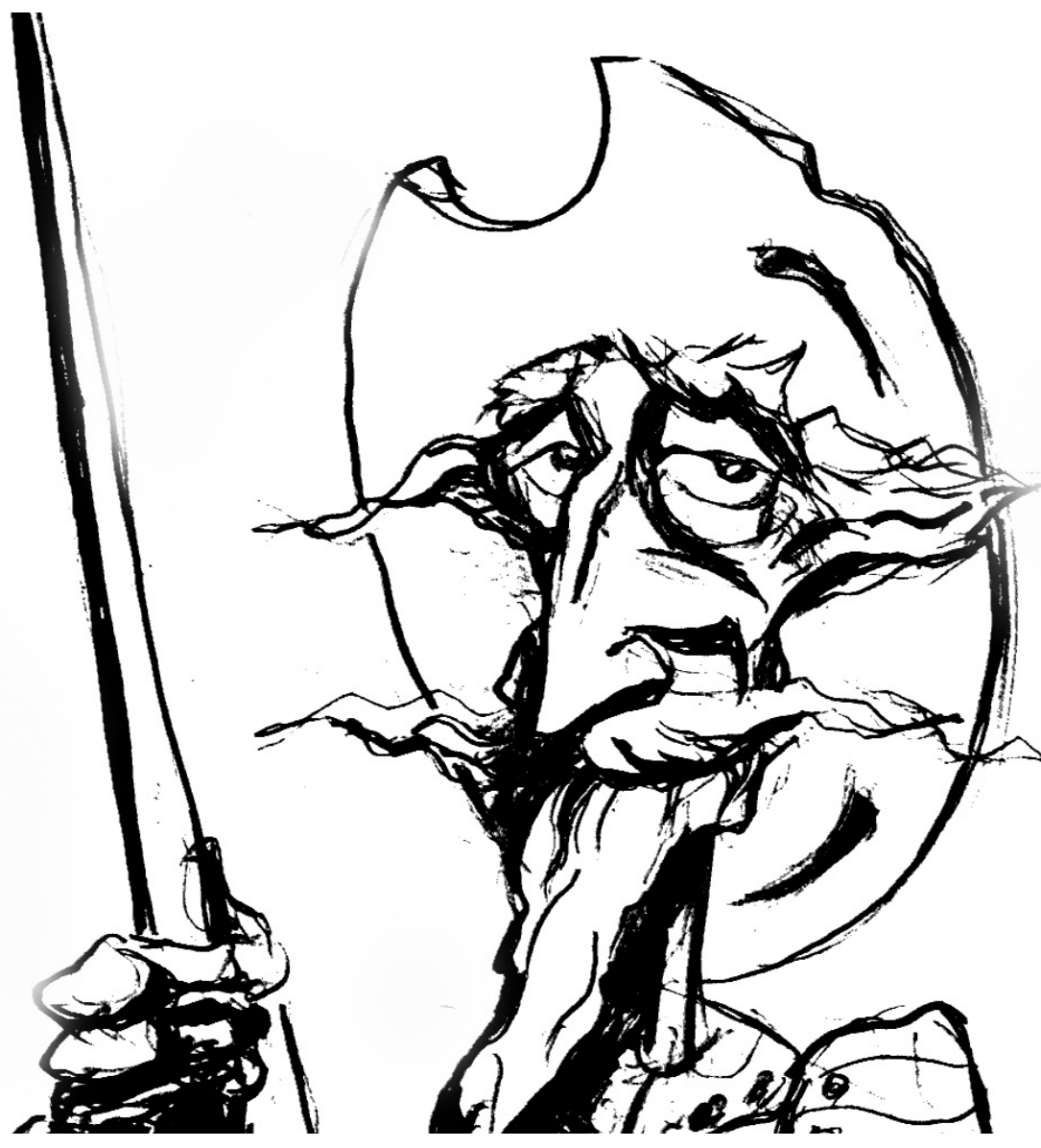

La legación de Gabriel de Aldunate de 1695 y la resignificación de Buenos Aires en las jerarquías territoriales de la Monarquía hispánica

[Carlos María Birocco] 



\section{La legación de Gabriel de Aldunate de 1695 y la resignificación de Buenos Aires en las jerarquías territoriales de la Monarquía hispánica*}

\section{The Legation of Gabriel de Aldunate in 1695 and the Resignification of Buenos Aires in the Territorial Hierarchies of the Hispanic Monarchy}

CARLOS MARÍA BIROCCO

\author{
Resumen \\ Durante el siglo XVII, el cabildo de Buenos Aires \\ perdió varias de sus potestades, entre ellas la de \\ intermediar en la venta de cueros en el puerto. \\ También intentó que los vecinos pudieran \\ comerciar libremente con sus propias \\ embarcaciones, ya que por presión del \\ Consulado de Lima el puerto fue clausurado. \\ Para conseguirlo, envió a un procurador a \\ negociar ante el Consejo de Indias, que no \\ consiguió su apertura, pero logró que se \\ nombrara a Buenos Aires capital de la \\ gobernación.
}

\section{Palabras clave}

Procuradores; Consejo de Indias; Buenos Aires; Cabildo; Río de la Plata

\begin{abstract}
During the seventeenth century, the Buenos Aires city council lost several of its powers, including that of mediating the sale of furs in the port. It also tried to allow residents to trade freely with their own boats, since the port was closed under pressure from the Consulate of Lima. To achieve this, it sent a procurator to negotiate before the Council of the Indies, which did not succeed in opening it, but did manage to name Buenos Aires as the capital of the governorate.
\end{abstract}

\section{Key Words}

Royal Procurators; Council of the Indies; Buenos Aires; Town Council; Río de la Plata

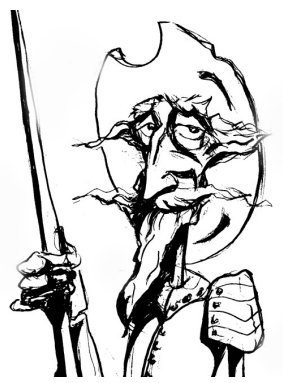

Recibido con pedido de publicación el 2 de marzo de 2021

Aceptado para su publicación el 10 de abril de 2021

Versión definitiva recibida el 2 de mayo de 2021

Carlos María Birocco, Universidad Pedagógica Nacional, Buenos Aires, Argentina; e-mail: cbiroc@yahoo.com.ar

\footnotetext{
* El autor agradece los comentarios y sugerencias de los evaluadores anónimos de la revista

Esta obra se publica bajo licencia Creative Commons. Atribución-NoComercial-CompartirIgual 4.0 Internacional
} 


\section{Las legaciones porteñas en Madrid y la cristalización de un discurso}

La Monarquía hispánica se mostró desde temprano consciente de sus dimensiones planetarias. Al mediar enormes distancias entre la metrópoli y sus posesiones transoceánicas renunció a imponerse a través de un orden jurídico inflexible y prefirió optar por una dinámica de gestión menos rígida, que le permitió acomodarse a las problemáticas dispares que enfrentó en esa multiplicidad de territorios y adoptar diferentes estrategias de acción. Para poder garantizar la gobernabilidad de sus dominios requirió de la colaboración de las élites locales, a las que se les dio participación en la toma de decisiones siempre que demostraran una actitud de acatamiento hacia las directivas de la Corona. Les confió, por un lado, la autogestión de una porción significativa de los asuntos de índole local y les reconoció, por otro, el derecho de cuestionar cualquier norma que contrariara esa autonomía de acción y exponer sus disconformidades en una instancia de negociación, a partir de la cual podían llegar a conseguir su modificación o derogación (Gaudin et al., 2017; Gaudin y Ponce Leiva, 2019).

El factor distancia provocaría una lógica dilación en la transmisión de las normas y en la circulación de la información entre los poderes centrales de la Monarquía y sus posesiones más remotas. Eso sucedió en el caso de Buenos Aires, un puerto que se encontraba apartado de la capital virreinal y de los principales circuitos de navegación oceánica. Visitado esporádicamente por navíos de registro, las órdenes y comunicaciones de la Corona a menudo se recibían con apreciable retraso. Esa posición geográfica marginal podría haber sido aprovechada por la dirigencia local para incrementar su autonomía, pero acabó por incidir en su contra, ya que su capacidad autogestora se vería cercenada por los agentes enviados por la Corona, que eran débilmente controlados por ésta. Desde mediados del siglo XVII, en efecto, el Cabildo porteño denunciaría repetidas veces a los gobernadores del Río de la Plata por hacer recortes a sus atribuciones e incumbencias y se vio obligado a hacer llegar sus súplicas al monarca para que les fueran restituidas.

Al igual que cualquier corporación ciudadana del conglomerado territorial hispánico, el ayuntamiento de Buenos Aires pudo invocar el derecho de súplica y hacer escuchar sus demandas en el Consejo de Indias. Desde los primeros años del siglo XVII, envió procuradores a Madrid para exponer sus reclamos y en un principio consiguió que estos fueran atendidos. Gracias a esas gestiones, en 1602 Felipe III permitió a los vecinos de esta ciudad que dispusieran de embarcaciones propias y enviaran en ellas cargamentos de cueros y sebo a los puertos de Brasil y Angola, y posteriormente al de Sevilla (Bonialian, 2018). Pero a finales de su reinado, la posición de este monarca se endureció y esas concesiones fueron revocadas. De ello resultó el "cierre" del puerto: los vecinos ya no pudieron navegar por su cuenta y debieron resignarse 
a esperar que llegaran navíos de registro desde la Península para vender su corambre y adquirir efectos europeos.

A partir de entonces, el Cabildo de Buenos Aires enfrentó a los poderes centrales de la Monarquía, ya que estos se obstinaron en mantener las restricciones que pesaban sobre el puerto. Entre 1623 y 1661 envió a Madrid sucesivas peticiones bregando por su reapertura. En aquellas cartas y memoriales, la vecindad porteña fue invariablemente retratada como una comunidad sumida en la pobreza, obligada a sostener un territorio donde la falta de riquezas minerales y de servidumbre indígena hacían imposible retribuir el esmero puesto en cumplir con el real servicio. Alejada de las otras ciudades españolas del virreinato del Perú, Buenos Aires debía abastecerse de la ropa, el armamento y las herramientas que precisaba para subsistir a través del tráfico oceánico, por lo que la derogación de las prohibiciones que pesaban sobre el puerto se convertía en un requisito ineludible si se esperaba que se mantuviera en pie. Con estos argumentos se esperaba que el rey, interesado en la conservación de este enclave y preocupado por asegurar el sustento de sus súbditos, restituyera el orden comercial anterior.

Esas presentaciones se caracterizaron por enarbolar un discurso de corte pactista: la relación entre el soberano y la vecindad fue representada como un orden justo, donde la búsqueda del bien común se fundaba en la reciprocidad (Amadori, 2015: 22-26). Cuando esa relación perdía el equilibrio, correspondía retornarla a su cauce virtuoso. Una manera de restablecer ese orden era por medio de la suplicación, es decir, a través de la presentación de memoriales y el envío de legaciones a Madrid. El objeto de ese acercamiento al monarca no era reprocharle su equivocación -presunción que resultaba inconcebible para la cultura política de la época, que enfatizaba el carácter paternal y justo de sus actos- sino sugerirle que al legislar se había fundado en información distorsionada o insuficiente. Los procuradores de Buenos Aires en la Corte afirmarían que los menoscabos sufridos por esta ciudad no se debían solamente a su pobreza de recursos, sino también a las calumnias de poderosos enemigos, que habían nublado el entendimiento del soberano y le habían impedido actuar con justicia. Esta estrategia discursiva, utilizada a lo largo de los dos primeros tercios del siglo XVII, reaparecería con escasas modificaciones al final de esa centuria. Esto nos hace preguntarnos por qué, pese a que los reclamos que presentó el ayuntamiento se ampliaron o variaron de asunto, aquellas argumentaciones se cristalizaron.

Ciertamente, las expectativas del grupo dirigente porteño seguían siendo recuperar las facultades y prerrogativas de las que la ciudad había sido gradualmente despojada, de las cuales la clausura del puerto había sido tan sólo la primera. Luego de más de una década de inacción, en 1685 el Cabildo intentaría formular nuevamente sus quejas frente al Consejo de Indias, pero una seguidilla de imprevistos le impidió hacerlo con éxito. En 1692, finalmente, 
decidió enviar una nueva legación encabezada por el capitán Gabriel de Aldunate y Rada, que presentaría dos memoriales al Consejo de Indias y expondría los reclamos del ayuntamiento. No viajó solo, sino acompañado por Juan de Prada y Gayoso, a quien se encomendó suplirlo en el caso de que se viera impedido a cumplir con ese encargo. Ambos recibieron el permiso del gobernador del Río de la Plata, Agustín de Robles, para pasar “a los reinos de España a representar a Su Majestad el estado de suma pobreza en que se halla esta república y sus vecinos y solicitar su remedio".

En este artículo indagaremos las causas que llevaron al ayuntamiento de Buenos Aires a enviar esta legación a la corte de Madrid y cómo fueron reflejadas en los argumentos que esgrimió el procurador para sostener sus reclamos. Asimismo, analizaremos las respuestas de la fiscalía del Consejo de Indias y la decisión final de este sinodio, que concedió algunas de las gracias solicitadas por el legado, pero rechazó la reapertura del puerto. Aunque esto último venía siendo objetado por la Corona desde hacía más de setenta años, ello no significó que dicha fiscalía estuviera por completo alineada con la poderosa corporación que se oponía a ellas, el Consulado de Comercio de Lima, sino que también se mostró crítica hacia éste. Aunque en este aspecto la gestión de Aldunate supuso un fracaso, en otros fue exitosa, principalmente al conseguir que Buenos Aires quedara reposicionada en la jerarquía de las ciudades que componían la Monarquía. Consiguió que le fuera conferida la titulatura de "Capital de Provincia", con todas las honras, preeminencias e inmunidades de que gozaban las demás capitales, y que en función a su nuevo rango se ampliara el número de los integrantes de su cabildo.

\section{La elección de un procurador}

Estudiar el envío de una legación a la corte de Madrid presupone, entre otras cosas, establecer la coyuntura que atravesaba la ciudad que la despachó, los propósitos con que lo hizo y la representatividad que le otorgó. Han de revisarse, además, los criterios seguidos al seleccionar a quienes la integraron y cotejar si al hacerlo fueron observadas las normas o costumbres locales (Álvarez-Ossorio Albariño, 1998). En el caso de Buenos Aires no había procedimientos ni tradiciones afianzadas que respetar: la presencia de procuradores de esta ciudad en la Corte fue un hecho excepcional, que jamás se había repetido en el transcurso de una misma década. Pero al escoger a Aldunate, puede decirse que los cabildantes fundaron su elección en determinados criterios de valoración. Se pusieron en relieve sus méritos como militar y su labor como teniente de gobernador y como cabildante, es decir, los servicios que había prestado al rey y a la república ciudadana.

¿Quién era Gabriel de Aldunate y Rada? Se trató, a las claras, del exponente de un sector que se estaba incorporando exitosamente a la vecindad 
porteña: el de los oficiales del Presidio local. A lo largo de las últimas tres décadas del siglo XVII, la Corona se había propuesto reforzar la guarnición de este puerto con el envío de contingentes de soldados, en su mayoría provenientes del norte y centro de España. Algunos de ellos llegaron a ser ascendidos a capitanes de una compañía y a vincularse con las parentelas más antiguas de la ciudad por medio del matrimonio. Este último mecanismo de alianza se convirtió en la llave para obtener su reconocimiento como vecinos (Birocco, 2017: 324-326).

Para los más afortunados, su promoción no se detendría allí y llegarían a ocupar un asiento en el ayuntamiento. Aldunate sería uno de ellos. Nacido en la villa navarra de Barasoain, se sumó en 1677, con veinticinco años, a una partida de soldados que fue remitida al Río de la Plata. Al cabo de quince meses de haber sentado plaza en Buenos Aires contrajo matrimonio con una porteña, doña Lucía de Aguilar y Salvatierra, de cuya familia poco sabemos. En 1681, cuando ingresó en el cuerpo de oficiales, ya era dueño de "casa y solar" en esta ciudad y padre de dos hijos: fue primero nombrado alférez de una compañía de caballería y luego ascendido al rango de capitán, en el que se mantendría hasta 1691, en que el gobernador Agustín de Robles le concedió la baja. Al finalizar su carrera militar, este navarro inició el cursus honorum civil: ese mismo año el Cabildo lo designó mayordomo del hospital de la ciudad, y al siguiente, alcalde ordinario y alférez real. A estos empleos se sumó el de teniente de gobernador y justicia mayor con que lo distinguió el gobernador Robles.

Aldunate había ganado su prestigio sirviendo a las armas. La autoridad suprema del Presidio de Buenos Aires, el comisario de la caballería Joseph de Herrera y Sotomayor, atestiguó que "en las ocasiones que se han ofrecido, ha salido al opósito de las invasiones que hacen los enemigos gentiles". Se distinguió, en efecto, en dos incursiones contra las etnias pampeanas: en la primera colaboró con el corregidor de Mendoza para contener una invasión a esa ciudad y la de San Luis; en la segunda, salió con una partida de soldados a patrullar los campos de Buenos Aires (Molina, 2000: 39-40). Cuando en 1680 los portugueses fueron desalojados por primera vez de la Colonia do Sacramento, se lo señaló como "de los primeros que han acudido con sus armas", mientras que en tiempos de paz participó de rondas y guardias "con toda puntualidad". Pero, aunque destacó sus virtudes militares -la valentía y el arrojo demostrados en la guerra y su escrupulosidad en el servicio durante la paz- el comisario consideraba igualmente notoria su actuación como alcalde del cabildo y como lugarteniente del gobernador: "le tengo por digno de los empleos en que Vuestra Majestad fuere servido ocuparle pues en los dos estados, militar y político, se halla con las aprobaciones referidas" (Levillier, 1915: 209-210).

Un segundo momento en la carrera de Aldunate se produjo tras su incorporación al "estado político". Era común que los militares retirados movilizaran su capital de servicio para ingresar en la administración pública: 
valorados por su experiencia y su prestigio, encontraban en ello una forma de hacer rentables los méritos que habían adquirido durante su trayectoria profesional y de ser premiados con nuevas dignidades (Ruiz Ibáñez y Muñoz Rodríguez, 2002: 238-239). El año en que se desempeñó como cabildante transcurrió sin sobresaltos para el ayuntamiento, dedicado mayormente a asuntos cotidianos como el abasto de la ciudad o la celebración de las fiestas patronales. Su asistencia a las sesiones del ayuntamiento fue tan puntual como lo había sido durante la rutina militar: jamás faltó a una de ellas. Esa voluntad inquebrantable de servicio sería reconocida por el resto de los capitulares al nombrarle procurador en la Corte. Estos lo destacaron tanto "por estar avecindado en esta ciudad con casa y familia, como por el amor que ha mostrado tenerle tan de hijo en todas las ocasiones que se han ofrecido". ${ }^{1}$ Aldunate era sin duda un foráneo, pero había correspondido a la ciudad que lo había adoptado como vecino sirviéndola con devoción filial.

En esta declaración del cabildo, el amor cobraba un significado político. Frente a la ausencia de una estructura burocrático-administrativa sólida, este término solía expresar los lazos duraderos que se establecían entre quienes formaban parte del aparato gubernamental y se garantizaban protección y seguridad mutuas, obedeciendo a unos imperativos de lealtad y fidelidad que tenían una fuerte resonancia religiosa (Cardim, 1999). En el caso de Aldunate se trataba del amor de un hijo, que correspondía con fidelidad y obediencia a la paternitas encarnada por la ciudad y representada por la corporación municipal. Esta última reconocía el "mucho amor" que había manifestado este navarro a su ciudad de adopción y le expresó que esperaba que su celo en el servicio no flaqueara durante su permanencia en Madrid.

Aunque el Cabildo de Buenos Aires confiaba en las habilidades de su procurador, temía por los imprevistos que podían llegar a presentarse. En la década anterior se había visto frustrado el envío de otro legado, Bernardo Gayoso, que había muerto en la nao que lo llevaba a España al recalar en Río de Janeiro. Para precaverse de un incidente similar, se nombró a otro vecino para que acompañara a Aldunate y lo reemplazara en caso de que sufriera algún percance. Se trataba de Juan de Prada y Gayoso, quien contaba con suficientes méritos políticos para secundarlo -en 1691 había sido alcalde ordinario- y les añadía un sugestivo capital relacional, ya que su esposa era la sobrina del obispo de Buenos Aires, fray Antonio de Azcona Imberto. Mantenía, además, un vínculo de cercanía con Aldunate, ya que era el padrino de uno de sus hijos. Ambos fueron citados a una sesión del ayuntamiento en que les fueron entregados poderes e instrucciones para que se encargasen de "los negocios que se ofrecen de la conveniencia de esta República". Con gestos de sumisión ritual, los dos se comprometieron a "permanecer en lo que se les encargare con todo

\footnotetext{
${ }^{1}$ Archivo del Extinto Cabildo de Buenos Aires, Tomo XVIII, Libros XII y XIII, pp. 69-73.
} 
celo y amor" y agradecieron el nombramiento, asegurando que "estimaban la honra que se les hace". ${ }^{2}$

El Cabildo se ocupó de suministrarles sólo una parte de los fondos que necesitaban para sus gestiones en Madrid: se les entregaron los 1.367 pesos que se habían recaudado durante 1692 en concepto de alcabalas. Muy poco de esta suma, sin embargo, estaría destinado a costear sus pasajes y la estadía en la corte, ya que se estipuló que 1.000 pesos serían invertidos por el procurador en "los negocios que de esta ciudad lleva a su cuidado". Esta escasa inversión en los gastos de las legaciones venía siendo un rasgo común desde la primera mitad de aquel siglo (Amadori, 2000). Entre tanto, se tramitaron los permisos de embarque ante el gobernador Agustín de Robles, quien los concedió sin poner reparos. Esto no era más que una formalidad en el caso de Gabriel de Aldunate, pues desde 1689 disponía de una licencia real para volver a su pueblo natal en Navarra para visitar a su madre viuda y de sus hermanos. Ambos pudieron así embarcarse con destino a Cádiz. Aldunate lo hizo en compañía de su hijo Bartolomé, de 12 años, y de dos sirvientes, el español Joseph de Figueroa y el negro libre Simón, "criados suyos por ser como son de su familia". Aunque Prada se sumó a ellos en la travesía, acabaría por no participar de las gestiones en la Corte: parece no habérsele asignado otro papel que el de suplir a su compañero en el caso de que enfermase o muriese. ${ }^{3}$ Lo que en apariencia era una legación dual fue en realidad una legación individual.

Como las privaciones que sufría la vecindad de Buenos Aires se debían en gran parte al poder omnímodo de los gobernadores del Río de la Plata, era sabido que los reclamos que presentaría Aldunate apuntarían a conseguir que se restituyeran al ayuntamiento porteño las facultades de que lo habían despojado. El gobernador Agustín de Robles no ignoraba que quedaría implicado tangencialmente en las denuncias, pero aun así autorizó la partida del procurador y sus acompañantes. El Cabildo obtuvo hábilmente su consentimiento escribiendo dos cartas para que Aldunate presentara en el Consejo de Indias: en una de ellas solicitaba al monarca que renovara el mandato de Robles por otros cinco años y en la otra celebraba la eficacia con que había contenido a los portugueses en la Banda Oriental, impidiéndoles que salieran de los límites de la Colonia do Sacramento. De esa manera se evitó que éste obstaculizara la partida de la legación, que se embarcó en uno de los navíos

\footnotetext{
2 Archivo del Extinto Cabildo de Buenos Aires, Tomo XVIII, Libros XII y XIII, pp. 75-76.

3 Sabemos que Prada llegó a la Península y permaneció allí por el testamento de su esposa, quien declaró: "fui casada y velada con Don Juan de Prada Gaioso, ausente en los reinos de España, a quien ha muchos años no tengo noticia si vive o muere". Antes de embarcarse, éste le había restituido su dote y los gananciales para que subsistiera durante su ausencia, y le prometió volver en los primeros navíos de registro que partieran para Buenos Aires, pero "no tan solamente no volvió, sino que aun siquiera no me ha escrito ni sé de él". Archivo General de la Nación de Argentina [AGN], IX-48-7-8 Escribanías Antiguas, f. 676v.
} 
de registro de Francisco de Retana que zarparon el 16 de mayo de 1693 en dirección a la Península.

\section{El procurador de Buenos Aires se presenta ante el Consejo de Indias}

Desconocemos las actividades de Gabriel de Aldunate entre que desembarcó en Cádiz y se estableció en Madrid. Ya se hallaba en esta ciudad en mayo de 1694, en que exhibió sus credenciales en la Corte. No fue hasta el 19 de junio en que el Consejo de Indias le solicitó que presentara los memoriales con sus pretensiones, y al cabo de dos días le informó que le concedería una audiencia cuando su agenda lo permitiese. Finalmente, el 8 de agosto se lo recibió en la sala en que los consejeros se reunían cotidianamente, en el ala norte del Real Alcázar. Allí, al ser interrogado sobre las pretensiones del cabildo de Buenos Aires, Aldunate haría "larga expresión de ellas". ${ }^{4}$

Como encargado de representar los intereses de los virreinatos del Perú y la Nueva España frente al soberano, el Consejo de Indias era su interlocutor obligado. Este formaba parte del sistema polisinodial que actuaba como aparato administrativo de la monarquía. Tenía un radio de competencia territorial, como los Consejos de Castilla, Aragón, Flandes e Italia, y se trataba al igual que estos de un órgano colegiado de carácter consultivo, al que le fueron otorgadas amplias competencias en los planos administrativo, hacendístico y judicial (Domínguez Nafría, 2001; Gaudin, 2017: 114-119). Entre ellas se encontraban las de atender las consultas de los funcionarios y las corporaciones que residían en los territorios ultramarinos, transmitirles las órdenes del rey, e intermediar en la distribución de los honores y los oficios (Amadori, 2013: 45-85). Esta última función -consistente en recibir las postulaciones de quienes pretendían ocupar cargos en el Nuevo Mundo o solicitaban mercedes, y en recomendar su aprobación o rechazo- fue, con mucho, la que generó el mayor volumen de las consultas tramitadas ante este Consejo, llegando durante la primera mitad del siglo XVII a abarcar casi dos tercios de las que le fueron presentadas. Esta exigencia aumentó durante el reinado de Carlos II, en que se pretendió que el sinodio centralizara la venta de oficios en América, pero esto último no llegó a conseguirse debido a la resistencia de los virreyes del Perú y la Nueva España, que no quisieron renunciar a sacar tajada de la venalidad (Infante, 2019: 296320). No obstante, dicho reinado se caracterizaría por la prevalencia de la designación por dinero del funcionariado indiano, cuya tramitación era una competencia de este sinodio (Sanz Tapia, 2012).

Las ciudades de la América Hispánica estuvieron obligadas a vincularse con el monarca a través del Consejo de Indias. El funcionamiento de sus

\footnotetext{
${ }^{4}$ El expediente completo de la gestión de Aldunate se encuentra en Levillier, 1915: 188-522. Salvo anotación a contrario, todas las referencias documentales provienen de allí.
} 
órganos de representación y gestión, los cabildos, estaba sujeto a la supervisión de este sinodio. En primer lugar, estos debían presentarle sus ordenanzas (que eran las cartas estatutarias que regían sus atribuciones y competencias) para que las ratificara y cobraran así fuerza de ley. También debían dirigirse a él si pretendían la ampliación de su planta funcionarial: por ejemplo, cuando se solicitaba un aumento en el número de sus regidores. Todo vecino que adquiriera una regiduría u otro empleo concejil de carácter venal tenía un plazo de seis años para hacer confirmar sus títulos en dicho Consejo. El mismo se constituía, además, en tribunal supremo cuando debían dirimirse conflictos de jurisdicción entre los ayuntamientos de dos ciudades, o entre éstas y los gobernadores.

La creciente afluencia de procuradores americanos parece haber entorpecido la labor del Consejo de Indias, ya que además de gestionar los encargos de las ciudades a las que representaban, estos aprovechaban su presencia en la corte para solicitar mercedes para sí y para otros particulares. Una real cédula del 11 de junio de 1621 prohibió a las ciudades americanas el envío de procuradores al Consejo, indicándoles que debían comunicarse con éste por medio de cartas. Sólo en asuntos de extrema relevancia o de urgente resolución podían ser dispensadas y enviar un representante, pero debían tramitar primero un permiso ante el virrey o la Real Audiencia correspondiente. Fue así como, en teoría, las corporaciones municipales perdieron la autonomía de enviar legaciones y sus reclamos debieron pasar por el tamiz de las mayores autoridades jurídico-administrativas locales antes de ser oídos en Madrid. Pero en la práctica las grandes urbes americanas consiguieron sortear esta prohibición y sus legaciones siguieron siendo recibidas sin objeciones por el Consejo.

El relajamiento progresivo en el cumplimiento de esta real cédula motivó que Carlos II se viera obligado a reiterarla el 24 de marzo de 1692. El Cabildo porteño debería haber acatado esa orden, pero el pliego que la contenía no llegó a su poder hasta después de que Aldunate se embarcase con destino a España. $\mathrm{Al}$ examinar las credenciales que presentó el procurador, el fiscal del Consejo de Indias recomendó que se lo admitiese, pues al provenir de una de las ciudades más recónditas del imperio, el envío de una legación no podía ser considerado una contravención "por lo remotas que están y necesidad que padecen". Aunque en un principio dudó en recibirlo, el Consejo acabó por aceptar esa recomendación. El factor distancia había jugado por una vez a favor de Buenos Aires.

Que sepamos, Aldunate fue admitido una sola vez en la sala de reuniones del Consejo. Para el resto de sus gestiones, que se extendieron a lo largo de dos años, se vio forzado a valerse de la vía escrita. Llevó desde Buenos Aires dos memoriales que presentó a los consejeros y que pudieron deberse tanto a su pluma como a la colaboración de los otros cabildantes. Sea quien 
fuese su autor, éste quiso hacer ostentación de una cultura erudita que no era propia, ya que las citas de juristas e historiadores fueron copiadas de un memorial anterior, que había sido escrito y presentado en España por otro procurador, Antonio de León Pinelo, en $1623 .{ }^{5}$ Se trata de un impreso del que existía un ejemplar en el archivo del cabildo, y de él también se extrajo la mayor parte de las reales cédulas y provisiones que se mencionan. La cristalización del discurso a la que aludimos en un principio se debe, en gran parte, a que esos memoriales se apoyaron en el mismo armazón documental y legal que diera León Pinelo al suyo. Al carecer los miembros del Cabildo de formación letrada, y al faltar en Buenos Aires bibliotecas en donde pudieran consultar otros textos jurídicos, poco pudieron hacer para dotarlos de nuevos fundamentos legales.

El eje de los argumentos presentados por Aldunate se basaba en el mismo principio que enunciara León Pinelo: "Ha de ser lo mismo regir que sustentar". El deber del soberano era asegurarse de que sus súbditos no padecieran privaciones. Los pobladores de Buenos Aires se consideraban abandonados por la mano regia, y así fue expresado por medio de los testimonios de un conjunto de varones preclaros, compuesto por los principales jerarcas de la iglesia porteña -el vicario general del obispado, el canónigo de la catedral y los priores de tres conventos- y por varios vecinos que habían ejercido los principales empleos políticos y militares. Dichos testimonios fueron reunidos en un informe por el síndico del Cabildo, Bernardino Antonio de Acosta, y adjuntados a los dos memoriales (Levilier, 1915: 212-258). El renombre de esos informantes pretendía dar mayor representatividad a sus declaraciones, todas ellas empeñadas en retratar la pobreza que aquejaba a la ciudad. El problema más agobiante, según aseguraban, era la escasez de mano de obra indígena y esclava, al punto de que "en muchas casas nobles y honradas se sirven de los hijos y de las hijas para el ministerio de cargar agua y otros actos serviles de la casa". Los vecinos apenas podían "sembrar cuatro granos de trigo", que luego perdían en tiempos de la cosecha "por no tener quien les ayude a cogerlo", y por tal razón el precio del grano había aumentado hasta tal punto que "los más dejan de comer pan".

Pero el propósito del informe de Acosta era resaltar las privaciones que sufría el cabildo desde que fuera despojado del principal de sus ingresos: la comisión que recibía por intermediar en la venta de cueros a los navíos de registro. En 1677, una real cédula había permitido a los capitanes de dichos navíos comprar corambre a los vecinos sin tener que dar participación de ello al ayuntamiento. A partir de entonces, sus rentas se habían vuelto insuficientes para sufragar las festividades de la ciudad, forzando a los cabildantes a comprometer sus propias fortunas en ello. Por ese motivo ningún vecino quería

\footnotetext{
${ }^{5}$ Por ejemplo, los párrafos que cita de la Historia general de los hechos de los castellanos de Antonio de Herrera y Tordesillas, las Relaciones universales del mundo de Giovanni Botero Benes, y la Americae pars quarta de Theodoro de Bry.
} 
ser alcalde ordinario, "pues las más veces suelen ir con gasto de muchos pesos", ni menos aún alférez real, debido a "los crecidos gastos que tiene en el paseo del estandarte real", mientras que los regidores habían abandonado sus empleos "por la mucha pobreza que padecen y no poder sustentar con el debido lustre y decencia sus personas y casas".

\section{Las pretensiones de la legación (I): la reapertura del puerto de Buenos Aires}

Aldunate no ignoraba que tendría que enfrentar las pretensiones del Consulado de Comercio de Lima, que contaba con aliados firmes en el seno mismo del Consejo de Indias. Esta poderosísima corporación, que agrupaba a los grandes comerciantes peruanos, se había convertido en la segunda mitad del siglo XVII en uno de los principales prestamistas a los que había recurrido la Corona durante sus crisis económicas. Era, además, quien había sostenido con sus contribuciones -principalmente mediante el pago del impuesto de avería- el alicaído sistema de flotas y galeones (Suárez, 2001). Desde hacía varias décadas, el Consulado venía ejerciendo presión para que el puerto de Buenos Aires siguiera clausurado. Acusaba a los mercaderes porteños de recibir efectos europeos a precios módicos, tanto de los cargadores de los navíos de registro como a través del contrabando, y de luego distribuirlos en otras regiones del virreinato del Perú, compitiendo deslealmente con quienes participaban del mentado sistema de flotas. También los responsabilizaba de la fuga de la plata, que gracias a su participación en el tráfico ilegal escapaba de los circuitos monopólicos.

El Procurador culpó al Consulado limeño de ocultar que las mayores fugas de metálico se producían en otra dirección: los puertos de la Nueva España. Aunque el tráfico de mercancías con Acapulco estaba prohibido, no lo estaba el envío de cargamentos de azogue de Huancavélica para las minas mexicanas, y en esos viajes se aprovechaba para intercambiar todo tipo de efectos, provocando así el "desagüe de plata". Pero el objetivo de Aldunate no era envestir contra los grandes comerciantes limeños por contrabandear en el océano Pacífico, sino denunciar su complicidad con los capitanes de los navíos de registro que llegaban al Río de la Plata. Cuando estos últimos se presentaban en Buenos Aires no lo hacían para comerciar con la vecindad local sino con los mercaderes del Perú y de Chile, que bajaban a este puerto a adquirir lo más voluminoso de su cargamento.

El Procurador apuntó a responsabilizar a los “dueños de los navíos de registro" de los padecimientos de la vecindad de Buenos Aires. A los porteños sólo les vendían "lo poco y desechado que les ha quedado", o bien lo trocaban por cueros, "que es la moneda que emplean los vecinos". Al no cumplir aquellos con la función de proveer manufacturas europeas a la vecindad, los gobernadores del Río de la Plata se habrían visto obligados a aceptar el ingreso 
de mercaderías de contrabando, que de acuerdo con el autor del memorial "arribaron a aquel puerto en ocasión de extrema necesidad, porque no las había ni las esperaban de buena entrada". A esta contravención, aseguró, se debía la supervivencia de este puerto: de no haberlo permitido, "despoblarían la tierra sus habitadores". El trato ilícito con buques de otras banderas, que hubiera sido difícil de negar, quedaba así justificado por el interés de la Monarquía en mantener poblado aquel puerto.

Aldunate bregó por la restitución de los permisos que Felipe III había concedido a Buenos Aires entre 1602 y 1621, por los que se había habilitado a los vecinos para conducir sus propios navíos al Brasil, el África portuguesa y los puertos de Cádiz y Sevilla, cargándolos de cueros y otros productos locales. Solicitó que se les volviera a conceder el envío de dos embarcaciones anuales a Cádiz "para socorro de las tres Provincias del Río de la Plata, Tucumán y Paraguay". Estos podrían cargar hasta 200 toneladas de frutos pagando al fisco 20 ducados por tonelada, y sólo traerían de retorno lo necesario "para abastecer la tierra", como cera, barras de hierro y aceite, asegurándose que "las mercaderías han de ser las más cómodas a la pobreza de ellas". Para evitar los recelos del Consulado de Lima, esa mercancías sólo podrían venderse en aquellas tres gobernaciones, y la aduana seca que funcionaba desde 1623 en la ciudad de Córdoba sería mudada a la ciudad de San Salvador de Jujuy, "que es la última del Tucumán", para impedir que circularan por fuera de ellas. El Consulado podría poner guardias no sólo en dicha aduana sino en Chile y en Potosí, "para que los que salen de ellas o bajan de ellas sean registrados".

Los memoriales que presentó Aldunate pasaron al fiscal del Consejo de Indias, que oficiaba como defensor de los intereses patrimoniales del monarca y era también el promotor de la justicia regia (López Nevot, 2013). Este reconoció que buena parte de las restricciones que pesaban sobre Buenos Aires rayaban en lo absurdo. Admitió la factibilidad de buena parte de las proposiciones del procurador, aunque sugirió ciertos ajustes. Recomendó que se permitiera a los porteños utilizar sus propias embarcaciones, convencido de que la mejor manera de que no hubiera fraudes ni ocultamientos era "navegándoles los vecinos de las mismas provincias, que como interesados celarían que los fraudes no les privasen de este beneficio". Pero aconsejó que se sirvieran de naves de mayor envergadura que las propuestas por el procurador: en lugar de recurrir a unidades de 200 toneladas, que corrían mayores riesgos de experimentar accidentes en el océano o de ser asaltadas por piratas, consideraba que era preferible un buque de 700 toneladas enviado cada dos años. Se daría un espacio equitativo en sus bodegas a los comerciantes del Río de la Plata, Paraguay y el Tucumán: para garantizar que cargasen cueros y otros frutos de la tierra con "la misma igualdad", el navío recibiría la visita del gobernador y del obispo de Buenos Aires, al igual que de regidores de esta ciudad y de las ciudades cabeceras de las otras gobernaciones. Agregó el fiscal que la aduana 
de Córdoba había sido poco más que inútil, pues al encontrarse rodeaba por una "campaña rasa de más de 100 leguas" no era difícil esquivar los controles. Pero si se la mudaba a San Salvador de Jujuy, el Consulado de Lima podría colocar allí guardas y comisarios para que actuara como una barrera más efectiva.

Aldunate se opuso a que el gobernador encabezara las visitas a las embarcaciones y pidió que las inspecciones fueran confiadas en exclusiva a los diputados del cabildo, pero el fiscal rechazó su propuesta de plano. Resultaba obvio que la corporación municipal pretendía monopolizar los permisos de navegación y controlar los cargamentos, a la vez que recuperar su intermediación en las ventas de cueros en el puerto, articulando ambas intervenciones con el fin de sacar de ellas un mayor provecho. El Consejo de Indias, sin embargo, siguió en contra de la reapertura del puerto de Buenos Aires y desaprobó tanto las proposiciones del procurador como las del fiscal: no estaba en sus planes alterar los circuitos monopólicos. Consideraba que con el envío periódico de navíos de registros desde Cádiz ya estaba asegurado el aprovisionamiento de Buenos Aires. De modo que el único de los puntos que se aprobó fue el traslado de la aduana seca a la ciudad de San Salvador de Jujuy, posiblemente no para complacer al cabildo porteño, sino para conceder al Consulado de Lima otra herramienta con que controlar el tráfico en las provincias andinas más ricas.

\section{Las pretensiones de la legación (II): el "repartimiento" de la corambre}

El Cabildo de Buenos Aires no había enviado un procurador a la Corte para enfrentar a un antagonista influyente pero remoto como lo era el Consulado de Lima. Tenía conflictos más graves que afrontar en su propia ciudad y puerto. Por un lado, la injerencia de los gobernadores, que habían ido cercenando uno tras otro sus privilegios, aprovechando la laxitud de los controles que fue característica de los reinados de los últimos dos Habsburgo. Por otro, las inmunidades que habían sido concedidas a los capitanes de los navíos de registro, quienes habían conseguido el permiso de pasar por encima de la corporación municipal para tener trato directo con los vecinos y comprarles cueros para transportar en su retorno a Cádiz.

Durante el siglo XVII, el principal recurso con que contó la vecindad porteña fue el ganado cimarrón. Este existía desde la fundación de la ciudad, pero se incrementó sustancialmente a partir de 1651, en que una epidemia de peste bubónica provocó el deceso de la mayor parte de los esclavos y peones que servían en las estancias, a raíz de lo cual los rebaños de vacunos se dispersaron por la pampa. Durante tres cuartos de siglo, los vecinos dedicaron la escasa mano de obra de que disponían a criar mulas y se resignaron a que aquellos ganados se volvieran montaraces, reclamándolos solamente en las 
ocasiones en que arribaban navíos al puerto y se hacía rentable la producción de corambre. Para poner orden en las expediciones que salían a la captura de reses (llamadas "vaquerías") y evitar que la explotación indiscriminada acabara con ellas, el Cabildo procedió a llevar una matrícula de "vecinos accioneros" (los propietarios originarios de los ganados dispersos y sus descendientes) y efectuó entre ellos el "repartimiento de cueros", es decir, la rotación de los permisos para salir a vaquear. También se hizo costumbre que fuera el ayuntamiento el que negociara las ventas de cueros a los capitanes de las embarcaciones y estableciera el precio por piel, luego de lo cual repartía un tercio de las ganancias entre los accioneros y conservaba para sí una comisión sobre las ganancias (Birocco, 2019).

Aunque la facultad de erigirse en intermediario obligado entre los productores de corambre y sus compradores no provenía de una concesión de la Corona, en un principio ésta toleró esa práctica. En 1677, no obstante, una real cédula concedió al capitán Miguel de Vergara, que visitó Buenos Aires al mando de dos navíos de registro, la libertad de poder negociar en forma directa con los vecinos, sin tener que dar cuenta al Cabildo de las transacciones. En 1681 llegarían al puerto las embarcaciones comandadas por el capitán Juan Tomás Miluti, a quien por medio de otra real cédula se habían otorgado libertades similares para proveerse de corambre. Este tipo de concesiones no constituían una novedad en el tráfico oceánico. Lo acostumbrado era que los permisos de navegación se confirieran a cambio de un contrato de prestación de servicios. Frente a la alarma producida por el avance de los portugueses en dirección al Río de la Plata, el monarca necesitaba de la colaboración de estos navieros para el traslado de los soldados y pertrechos militares con los que pretendía reforzar la guarnición de Buenos Aires, y una manera que encontró de atraerlos fue la de ofrecerles ventajas en la compra de productos locales.

Una de las misiones de Aldunate fue conseguir la derogación de esas reales cédulas y procurar que el Cabildo recuperara su rol de intermediario. El Procurador inició una intrincada negociación con el Consejo de Indias que le llevó la mayor parte de su estadía en la corte. Según alegó, con la intervención el ayuntamiento se evitaba "que los vecinos que no tienen acción a los ganados vayan a las vaquerías y matanzas" y que "los mismos accioneros [se] excedan en las matanzas", perjudicándose unos a otros. Pero desde la licencia que se otorgó a Miguel de Vergara, los navieros pudieron “comprar la corambre sin que preceda repartimiento" y no hubo control sobre la procedencia de las pieles que adquirieron. Como se dijo anteriormente, estos reservaban la porción más selecta de su cargamento para venderla a los comerciantes que llegaban desde el Perú y Chile, que la pagaban en plata, y luego canjeaban los saldos a los porteños por corambre. Al efectuar este trueque, subían en un 20 o 30 por ciento el precio de los efectos europeos y otorgaban a los cueros un precio irrisorio. Cada cuero, que antes de 1677 era valuado en 11 reales, ahora lo era en 8 reales. 
Afirmaba el procurador que esto sólo se normalizaría si las transacciones volvían a ser supervisadas por una diputación de dos cabildantes. También en este caso pidió que no se le diera intervención al gobernador ni a sus tenientes.

Aquí el fiscal se mostró opuesto a lo propuesto por Aldunate. Consideraba que cualquier pretensión de propiedad sobre los ganados cimarrones iba en contra del derecho natural. Citó las ordenanzas de la mesta de Nueva España, que en su décimo capítulo disponían que cualquiera podría apoderarse de ellos si "se hubiesen vuelto a su fiera naturaleza y no estuviesen debajo de la mano y custodia de los que fueron sus dueños". Por tal razón le parecía aceptable que cualquier vecino saliera a la captura de las reses y vendiera luego sus pieles a los navieros, pues a su entender aquellos animales eran bienes comunes, que estaban a disposición de todos y no podían ser juzgados propiedad de nadie. Por otro lado, estaba al tanto de que hasta entonces el cabildo de Buenos Aires había procedido con poca equidad en los repartimientos, privilegiando a algunos vecinos por amistad o parentesco y excluyendo a los demás. Aceptaría que las salidas a vaquear siguieran estando reguladas de esa manera, pero sólo si las licencias fueran concedidas por una comisión compuesta por el gobernador, los oficiales de la Real Hacienda y el obispo, pues de lo contrario "se seguirá que los más poderosos pretendan el dominio en el ganado alzado y no consentir que los pobres usen del beneficio que les permite el derecho de gentes".

Pasado un año, Aldunate se permitió insistir sobre el asunto. El Cabildo de Buenos Aires, según afirmó en una nueva presentación, era el más indicado para repartir las licencias para vaquear y para intermediar en la venta de la corambre, ya que al llevar la matrícula de los accioneros era el único que tenía presente quienes eran los vecinos que contaban con títulos sobre el ganado cimarrón. Resulta llamativo cómo el fiscal del Consejo de Indias cambió en forma radical de posición, abandonando la tesis de que dicho ganado debía ser considerado un bien común. Posiblemente se debiera a que un año atrás había basado su opinión en normas que eran extrañas a las usanzas del Río de la Plata (las de la mesta mexicana) pero luego fue puesto al tanto de estas últimas. Reconoció que en Buenos Aires no podían salir a vaquear "más que las personas que según la costumbre y libros del ayuntamiento están declarados por accioneros", y pidió que sólo a estos les fuera reconocido un derecho que habían adquirido "por costumbre y estilo anticuado" y que no se les impusiesen nuevas reales cédulas sin ser escuchados.

Por entonces, se preparaban para partir hacia el Río de la Plata los navíos de registro del capitán Carlos Gallo Serna. Este había ganado una real cédula análoga a las que habían sido concedidas a Vergara y a Miluti, que le permitía comprar corambre a quien quisiese sin que pudiesen interferir el gobernador ni el cabildo. El Fiscal no se atrevió a contradecirla, pero propuso una solución para dejar conformes a ambas partes: este naviero podría comprar libremente 
los cueros a los vecinos accioneros, pero no a otras personas que no hubieran sido matriculadas como tales. Respecto a los términos de la transacción, se dispondría que dos diputados del ayuntamiento y dos diputados de los accioneros se reunieran con Gallo Serna y ajustaran los precios "según su bondad y el valor de cada cuero", para que si alguno de los accioneros no dispusiese de plata para comprar efectos europeos pudiera "permutar su corambre a estimación justa".

En este caso, el parecer del fiscal sería el adoptado por el Consejo de Indias. Por recomendación de este sinodio, Carlos II ordenaría que se respetara "la costumbre que ha tenido la ciudad de capitular por medio de dos diputados con los dichos dueños de navíos el número de cueros que necesitan y su precio". Dispuso que en adelante el Cabildo volviera a repartir las licencias para hacer corambre entre los accioneros, "regulando un tanto por ciento de pieles a cada uno", sin dejar excluido a ninguno de ellos. El gobernador o su teniente habrían de asistir a ese reparto, pero no tendrían ni voz ni voto en él, aunque podrían escuchar en justicia a quienes se sintieran agraviados. Con esta real cédula, la aplicación del principio de bien común al ganado cimarrón quedó definitivamente desestimada: el monarca dispuso que aquellos vecinos que sin tener derecho ni título se adueñasen de los ganados fueran castigados.

\section{Las pretensiones de la legación (III): la recategorización de Buenos Aires}

Hubo otra situación conflictiva que movió al Cabildo porteño a enviar una legación a la corte de Madrid: el despojo gradual de sus facultades que había sufrido en manos de los gobernadores del Río de la Plata. Desde hacía dos décadas, estos últimos gozaron de una creciente libertad a la hora de tomar decisiones. Ello se debió en gran medida a la dificultad de someterlas a la consulta de sus superiores inmediatos, los virreyes del Perú, que residían a enormes distancias de Buenos Aires, en momentos en que los portugueses acababan de asentarse frente a esta ciudad, fundando Colonia do Sacramento.

En ese contexto de confrontación con una potencia rival, la Corona se había empeñado en reforzar la guarnición de este puerto y había colocado la provincia en manos de gobernadores con probados antecedentes militares (Trujillo, 2017). La relajada vigilancia ejercida sobre estos les permitió imponerse sobre el cabildo, a medida que éste se debilitaba a causa de la pérdida progresiva de sus integrantes: de los ocho regidores con que había contado en 1665, sólo quedaba uno en ejercicio en 1695, y otros empleos venales con asiento en la sala consistorial, como el depositario general y el alcalde provincial de la Santa Hermandad, dejaron de contar con quien los ocupara. El avance de los gobernadores sobre las potestades del ayuntamiento pudo apreciarse en los más variados aspectos: desde su falta de consideración a las 
normas de prelación y etiqueta hasta la militarización de la justicia ordinaria y del mantenimiento del orden público en la ciudad.

En el segundo de los memoriales presentado por Aldunate se quisieron explicar al Consejo de Indias las consecuencias de estos excesos. Se remarcó, para empezar, que las fortificaciones en Buenos Aires adolecían de serias deficiencias: expresaba el memorial que "el que hoy llaman fuerte son una flacas paredes de tierra" y que sus flancos debían ser continuamente reparados. El único recurso defensivo con que se contaba eran los efectivos de la guarnición, que por entonces sumaban unos 800 hombres. Estos, no obstante, estaban insuficientemente equipados y mal pagados, pues recibían sus sueldos -que se les enviaban desde Potosí a través del sistema de los reales situadoscon muchísima demora, al punto de que en 1695 se les estaban debiendo tres años de paga. A causa de las privaciones, muchos soldados habían abandonado sus puestos y otros habían llegado a tramar un motín, que había sido trabajosamente contenido por el gobernador Agustín de Robles. El Procurador alertó al Consejo sobre la peligrosidad de estos retrasos en el pagamento y sobre la urgente necesidad de que el mismo se regularizara. Esa inestabilidad perjudicaba no sólo a la tropa sino a los oficiales del presidio, que al tener que sostener un estilo de vida acorde a su rango se habían visto forzados a incursionar en el comercio al menudeo, lo que los llevó a competir con los vecinos. Solicitó que se les prohibiera que abriesen casas de comercio y que a los que insistieran en hacerlo se los diera de baja, "porque en este empleo se vicia el de su verdadera profesión".

En las denuncias de Aldunate se percibe claramente la alianza que tramaron los últimos gobernadores del período Habsburgo con la cúpula militar, a la que obsequiaron con dádivas y privilegios. Ello puede apreciarse en las prebendas que se confirieron a los sargentos mayores del presidio, que tenían bajo su mando a las ocho compañías de caballería e infantería de la guarnición. Una de ellas fue la de aprovisionar de carne a la tripulación de los navíos de registro, con la que se perjudicaba a los vecinos que habían sido habilitados por el cabildo para enviar reses al matadero y proveer de carne a la población. Otra fue la habilitación para mantener casas de juegos públicos en la ciudad, al parecer como una forma de acrecentar sus ingresos. El Procurador propuso que sólo se le permitiera que mantuvieran una en el cuerpo de guardia, donde las mesas de juego estarían reservadas para oficiales y soldados, y que el resto fueran clausuradas "por los muchos inconvenientes que suceden con la gente de servicio y ser estorbo de la quietud".

Aldunate habría de rechazar en sus memoriales los procedimientos intrusivos de los gobernadores, que a menudo menospreciaban las preeminencias de la vecindad o las competencias del cabildo. En Buenos Aires no era infrecuente que aquellos oficiaran como tribunal de primera instancia en casos de justicia ordinaria, y se reservaron la resolución de las causas que 
implicaban a la gente de mar, particularmente a las tripulaciones de los navíos de registro, impidiendo al ayuntamiento intervenir en ellas. El Procurador denunció no sólo esta pretensión de exclusividad, sino el uso abusivo que hacían de la fuerza. Cuando un gobernador ordenaba detener a algún vecino a causa de un delito, se valía de un partida de soldados y luego los recluía en los sótanos del fuerte o en la torre del Riachuelo: con ello se contrariaban las leyes de Indias, que indicaban que al dictaminarse una prisión se debía notificar al alguacil mayor del cabildo, quien contaba con sus propios calabozos. El mantenimiento del orden público también incumbía al alguacil mayor, cuyos alcaides rondaban las calles de la ciudad a todas horas. Estos, no obstante, no podían interponerse cuando la soldadesca montaba bullicio por las noches o violentaba físicamente a los vecinos, ya que el gobernador les había prohibido que interviniesen "en los lances que se ofrecen con los soldados" en reconocimiento a sus fueros, que los colocaba por encima de la justicia ordinaria.

Las medidas que reclamó Aldunate para proteger al cabildo y a la vecindad de Buenos Aires contra el amenazante poderío de los gobernadores fueron en casi todos los casos admitidas como justas por el Consejo de Indias y motivaron la emisión de un conjunto de reales cédulas que buscó brindarles una reparación. En lo que toca al ayuntamiento, el Procurador solicitó que su planta fuera ampliada mediante la creación de seis nuevas regidurías: en su opinión, quienes ocuparan dichos empleos no debían acceder a ellos por compra sino por designación, pues consideraba que no había en la ciudad quien pudiera pagar por ellos. Esta apelación a la pobreza era visiblemente una maniobra del Cabildo, que pretendía repartirlas entre sus allegados, pero la misma fue desbaratada por el fiscal, que juzgó inaceptable la pretensión de Aldunate. Carlos II, mediante una real cédula, acabaría por conceder esas regidurías, pero determinó que fueran vendidas en almoneda pública, tal como era costumbre. A través de otra real cédula, el Monarca aprobaría las ordenanzas del cabildo, que habían sido escritas en 1664 pero nunca refrendadas por su firma. Fueron primero presentadas al Consejo de Indias, quien las devolvió con algunas anotaciones marginales para que fueran modificados algunos de sus artículos, pero los cambios que sugirió fueron de escasa significancia. Las mismas regirían en Buenos Aires durante más de un siglo.

El Procurador también salió en defensa de las prerrogativas oligárquicoestamentales de la vecindad. Fue en este campo donde su gestión cosechó los mayores logros. En uno de los memoriales que presentó se reclamaba que se diera preferencia "a los vecinos españoles o hijos de beneméritos" para ocupar los oficios políticos y militares. Al conseguir que fuera derogada una real cédula de 1680 que impedía a los naturales de Buenos Aires sentar plaza de soldados en el presidio, logró que pudieran ingresar a la carrera de armas. A su vez, 
denunció los abusos que cometían los gobernadores al forzar a los vecinos a colaborar con las tropas veteranas. Como la guarnición no contaba con los efectivos suficientes para rotarse en los puestos militares sobre el río y salir a patrullar periódicamente los campos, se los obligaba a cumplir con esas tareas, alegando que formaban parte de las milicias urbanas y debían servirlas con sus propias armas y cabalgaduras. Aldunate solicitó que los gobernadores "con el título de milicia auxiliar no obliguen a los vecinos a guardias ni malocas" y obtuvo una real cédula que lo prohibió.

Aldunate denunció la arbitrariedad con que los gobernadores impedían a los vecinos circular dentro de la jurisdicción territorial de la ciudad. Su libertad de movimiento se había visto coartada hasta tal punto que no se les permitía visitar sus haciendas de campo sin obtener un permiso del gobernador. Desde los tiempos de Joseph de Herrera y Sotomayor, antecesor de Agustín de Robles, se les había impuesto un tributo de la tercera parte de las maderas que cortasen en las cercanas islas del delta del Paraná y se les habían impedido que pasasen a la Banda Oriental a buscar maderas, leña y carbón. El Procurador solicitó al Consejo de Indias que se diera fin a esas imposiciones y consiguió que Carlos II reiterara una real cédula de 1676 que garantizaba a los vecinos el derecho de cortar maderas a una y otra orilla del estuario.

Pero sin duda el éxito mayor de esta legación fue el de conseguir que se modificara el estatus que poseía la ciudad de Buenos Aires en el seno de la Monarquía hispánica. Aldunate acusó a los gobernadores de haber "atendido más a lo militar que a lo político" y de alterar el ceremonial cívico-religioso en la ciudad, no respetando el orden de las precedencias que aseguraban a los miembros del cabildo los asientos más honrosos en la iglesia o en los palcos que se montaban durante las fiestas. Con tamaña falta de consideración, Agustín de Robles y sus predecesores habían ofendido al cabildo como cuerpo, en atención a que se trataba del órgano representativo de la vecindad de una ciudad que era cabecera de una gobernación. El Procurador reclamó que se diera a Buenos Aires "el tratamiento que le toca por ciudad capital". El 31 de diciembre de 1695, Carlos II respaldó su pedido con una real cédula que declaraba a esta ciudad capital de la provincia del Río de la Plata. Ordenó que en adelante fuera "atendida y tratada como tal y se le guarden y hagan guardar las honras, preeminencias, prerrogativas, inmunidades y excepciones que por esta razón le pertenezcan y deban guardársele según y como se hace con las demás ciudades capitales de las otras provincias de mis Reinos de las Indias". Con ello no sólo se aumentaban los privilegios de que debía disfrutar el ayuntamiento como corporación, que a partir de entonces serían análogos a los que gozaban los "grandes de España", es decir, la alta nobleza peninsular. También se reconsideraba el rango que tenía Buenos Aires en el conjunto de las ciudades americanas, pues el protocolo regio le reservó desde entonces un lugar por detrás de las capitales de los virreinatos. 


\section{A modo de conclusión: logros corporativos y logros personales de un procurador}

Aunque sus negociaciones en la Corte representando al cabildo de Buenos Aires sólo se extendieron entre 1694 y 1696, Aldunate permanecería durante casi un lustro en la Península. Retornaría a inicios de la primavera de 1698, a bordo de uno de los navíos de registro de Carlos Gallo Serna. Al poco tiempo de haber arribado cayó enfermo, lo que le impidió presentarse en el ayuntamiento para rendir cuentas de su gestión. El 3 de octubre, el alcalde ordinario Antonio Guerreros y el síndico procurador Pedro Pesoa de Figueroa decidieron apersonarse junto al convaleciente para recibir de sus manos los pliegos que contenían las veintiséis reales cédulas que había ganado a favor de la ciudad. La escena transcurrida en torno a su lecho no careció de ritualidad: sin levantarse de él, Aldunate "enseña y entrega" a los dos cabildantes los "instrumentos y despachos" que ha traído desde Madrid, y a medida que lo hace, los contenidos de los pliegos son resumidos en un acta por un escribano. Concluido el inventario, el alcalde Guerreros declara que, en consideración a su falta de salud, se lo libraba de la sanción que le hubiera correspondido por no haberse presentado en la sala consistorial. ${ }^{6}$

El cabildo de Buenos Aires había tenido la opción de contratar los servicios de alguno de los agentes de negocios que residían en Madrid, quienes estaban más familiarizados con los procedimientos administrativos y sin duda disponían de contactos e influencia en el seno del Consejo de Indias. Pero ello le habría insumido un dispendio mayor de recursos para invertirlo en un intermediario de cuya confiabilidad y eficiencia sólo tenían vagas noticias, y al que no podían instruir sino por medio de misivas. Al confiar la gestión a Aldunate, la corporación logró mantener la comunicación política con la corte a bajos costos. Como éste tenía que emprender el viaje para atender asuntos familiares en su Navarra natal, en parte lo solventó con medios propios, aligerando los gastos de la corporación. El Procurador, por su parte, pudo combinar la defensa de los intereses del ayuntamiento en la corte madrileña con la resolución de asuntos personales y con el emprendimiento de otras gestiones de carácter privado, tanto en favor propio como de otros particulares.

Más allá de la fiabilidad que les inspiraba un procurador que había salido de sus propias filas, los cabildantes que lo designaron no ignoraban que su actuación iba a transcurrir a miles de leguas de la ciudad y que éste podía tomar decisiones que discordaran con los mandatos que había recibido. El hecho de que llevase consigo dos memoriales -de los que ya expresamos nuestras sospechas de que Aldunate pudo no haber sido su único autor o, quizás, ni siquiera fue uno de ellos- fue un recaudo que tomó la corporación

${ }^{6}$ AGN IX-48-8-4 Escribanias Antiguas, f.172 
contra un posible exceso de autonomía, "encadenándolo" a un listado de reclamos. Fue una forma de sujetarlo a un plan de acción. Dicho plan se tornó inamovible, ya que uno de los obstáculos que enfrentaban los procuradores que procedían de los territorios ultramarinos más remotos era la imposibilidad de recibir nuevas instrucciones de sus mandatarios. Como observa sagazmente Guillaume Gaudin, la comunicación sufría de "rugosidades" causadas por las formidables distancias que separaban al legado de sus mandatarios (Gaudin, $2017 b$ ). Ellas podían apreciarse, por ejemplo, cuando la correspondencia llegaba tardíamente o cuando un mandato transmitido por una misiva era malinterpretado o mal ejecutado. En el caso de Aldunate, no existió siquiera la posibilidad de que algo de esto ocurriera, ya que durante los dos años que duraron sus gestiones en la corte, la conexión marítima entre Buenos Aires y Cádiz estuvo suspendida y no pudo recibir correspondencia del cabildo.

Es importante destacar que los miembros del Consejo de Indias no se mostraron necesariamente opuestos a los pedidos del procurador. Sólo fueron inflexibles respecto a la reapertura del puerto de Buenos Aires, lo que no constituyó una novedad, ya que esa había sido la postura de este sinodio a lo largo de más de seis décadas. Pero en los demás asuntos tratados, sólo se negaron a hacer concesiones en aquellos casos en que se veía perjudicado el erario regio. Las opiniones del fiscal del Consejo en ocasiones se mostraron maleables y siempre que variaron fue para acercarse a las posiciones del procurador. Ello ocurrió, por ejemplo, cuando se trató el problema de las ventas de cueros de ganado cimarrón. En una primera instancia, quiso que esas transacciones se ajustaran a la normativa que se aplicaba en el territorio novohispano. Pero cuando comprendió que ésta no se adecuaba a la coyuntura rioplatense cambió de posicionamiento, aceptando la vigencia de las costumbres que regían en Buenos Aires. He aquí como un agente letrado de la Corona reconocía los saberes de un procurador que, aunque a las claras era un infraletrado, contaba con sólidos conocimientos sobre los usos y las prácticas sostenidos por el cabildo porteño, todo lo cual constituía una parte sustancial del derecho local.

Ahora bien, ¿qué tan rentable fue para Aldunate su permanencia en la corte de Madrid? El cabildo de Buenos Aires no parece haber remunerado sus servicios: ni en los libros de acuerdos ni en los libros de la mayordomía (que expresaban los movimientos de la caja de la corporación) han quedado evidencias de ello. Sí lo hizo, en cambio, el cabildo de Santa Fe, que también lo nombró procurador. Sus encargos fueron, en comparación con los del ayuntamiento porteño, bastante exiguos: solicitó a la Corona que se le permitiera el nombramiento de regidores anuales, que se prorrogara el cobro del derecho de romana y que se aprobara la fundación de una reducción de indios chaqueños. Aldunate consiguió dos reales cédulas a su favor y exigió a cambio el pago de 340 pesos por sus gestiones. 
A pesar de que su licencia para embarcarse a Cádiz sólo lo había autorizado a llevar consigo la ropa de su uso y el dinero que necesitara para sus gastos personales, no puede descartase que haya transportado clandestinamente cueros $u$ otros frutos para vender en la Península o que llevara ocultas otras sumas de plata para invertir en efectos de Castilla. No obstante, creemos que la rentabilidad de su viaje provino de haber oficiado en la Península como agente de negocios de importantes comerciantes de Buenos Aires y quizás también de las provincias vecinas. En una carta que el mercader más opulento de la ciudad, Miguel de Riblos, remitió a uno de sus proveedores en Cádiz, se menciona a nuestro procurador, a quien encargó que supervisara la entrega de una remesa de mercaderías para que fueran embarcadas en los primeros navíos de registro que zarparan hacia el Río de la Plata. Rogó a su corresponsal, en efecto, "se sirva entregarle al capitán Don Gabriel de Aldunate o al capitán Dn Miguel de Vergara del Orden de Santiago el dinero que le pidieren". ${ }^{7}$

Aldunate aprovecharía su estancia en la corte de Madrid para gestionar para sí una merced. Consiguió que el Consejo de Indias le otorgara el empleo de corregidor de la provincia peruana de Andahuaylas, que había quedado recientemente vacante. De regreso en Buenos Aires, presentó su nombramiento al gobernador Robles, lo mismo que un despacho de la Casa de Contratación que le permitía desplazarse a aquella provincia sin que le pusieran demoras ni le exigieran otras credenciales. A comienzos de 1699 se aprestó a dirigirse al Perú, acompañado por su esposa y por uno de sus hijos pequeños. Quedaron en Buenos Aires su hijo mayor, Bartolomé (quien, como se recordará, había viajado con él a España y tenía por entonces unos 18 años) y su hija María. Poco antes de partir, casó a ésta con el guipuzcoano Juan de Azcue, a quien entregó una sustanciosa dote, que incluía la espaciosa casa que había pertenecido a la familia. Aldunate dedicaría los escasos meses que permaneció en la ciudad antes de trasladarse a su nuevo destino a comprar mercancías, en las que invirtió una suma cercana a los 3500 pesos. Le fueron provistas por los cargadores de los navíos de Gallo Serna y por el mercader Miguel de Revilla, con el propósito de poder beneficiarlas en las provincias andinas.

La experiencia de Aldunate como legado de una ciudad periférica dejó en claro que era el poder contributivo de cada corporación lo que definía sus probabilidades de negociar exitosamente con la monarquía. A lo largo de tres cuartos de siglo, los mercaderes porteños no pudieron conseguir que se los habilitara para emprender la navegación por su cuenta por presión de los comerciantes agrupados en torno al Consulado de Lima, que recelaban de su competencia en el tráfico atlántico. No obstante, estos últimos no bregaban por la total desconexión de Buenos Aires con la metrópoli, sino que sólo pretendían

\footnotetext{
${ }^{7}$ AGN Sucesiones 8122. Juan Goicochea contra Miguel de Riblos
} 
mantener la ruta entre Cádiz y este puerto bajo su control, ya que como denunció Aldunate, fueron los principales adquirentes de los efectos europeos que llegaban al Río de la Plata en los navíos de registro. Al ser dicho Consulado quien solventaba el sistema de flotas, pudo ejercer su dominio no sólo sobre la ruta principal que conectaba a los puertos andaluces con el Caribe, sino también sobre las rutas secundarias.

Buenos Aires no fue sino un puerto terminal en una de esas rutas. Pero su carácter periférico no se medía tanto por las distancias como por la pobreza de los recursos que podía ofrecer, que no incentivaban a la Corona para darle a sus pobladores un mayor protagonismo en los circuitos comerciales. Un estudio sobre las legaciones enviadas por Guatemala a la corte de Madrid nos ofrece la posibilidad de establecer un parangón entre esta gobernación centroamericana y la del Río de la Plata, que servirá para entender el carácter periférico de ambas: su autora manifiesta que en aquella "existían zonas cercanas aún no incorporadas a los reinos ibéricos; jurisdicciones contrapuestas entre gobernaciones; presencia de súbditos y vasallos de otras monarquías" (Bahena Pérez, 2020). También en el Río de la Plata podía observarse la existencia de zonas próximas aún no dominadas por los españoles (la extensa planicie pampeana, a unos pocos cientos de leguas de Buenos Aires, o los bosques habitados por las etnias chaqueñas en las cercanías de Santa Fe), lo mismo que conflictos jurisdiccionales no resueltos (con la lindera gobernación del Tucumán, que implicaban a Santa Fe, Buenos Aires y Córdoba) o la contigüidad con los territorios de otra monarquía (los portugueses en Colonia do Sacramento). Todo ello contribuía a complicar la sostenibilidad de la presencia española, cuyos perspectivas de rentabilidad eran, sin lugar a duda, menores que las inversiones que debía hacer la Monarquía para mantenerse en aquella región.

La derrota que sufrió Aldunate al solicitar la reapertura del puerto no opacó los triunfos que obtuvo en otros asuntos que planteó ante el Consejo de Indias. El más significativo fue el reconocimiento que se dio a la ciudad de Buenos Aires al otorgársele el rango de capital, pero también consiguió la restitución de los derechos y privilegios de su cabildo y su vecindad. Varias de las reales cédulas que ganó, no obstante, acabarían siendo ignoradas por Agustín de Robles, que se resistió a darles cumplimiento. La que disponía la creación de seis nuevas regidurías para ampliar la planta funcionarial del ayuntamiento, por ejemplo, sólo sería obedecida por su sucesor, Manuel de Prado y Maldonado, en 1701, mientras que franqueaba a los porteños el uso de barcazas para traer leña, carbón y maderas desde la Banda Oriental fue desoída por los sucesivos gobernadores hasta 1711, en que Felipe V tuvo que reiterarla. La arbitrariedad con que se manejaron los gobernadores del Río de la Plata ha de ser remarcada, en conclusión, como la principal secuela de las distancias que separaban esta provincia de la metrópoli, ya que no alcanzó a ser moderada por 
la Corona hasta después de instalada la dinastía de los Borbones, en que ésta reafirmó su presencia por medio de dispositivos más eficientes de control.

\section{Bibliografía citada}

Álvarez-Ossorio Albariño (1998). “Corte, reinos y ciudades en la monarquía de Carlos II: Las legaciones provinciales", en Pedralbes: Revista d'història moderna, p. 221-250.

Amadori, Arrigo (2013). Negociando la obediencia. Gestión y reforma de los virreinatos americanos en tiempos del conde-duque de Olivares (1621-1643), Madrid: Consejo Superior de Investigaciones Científicas.

Amadori, Arrigo (2015). "El comercio rioplatense y la construcción discursiva de un espacio político por el cabildo de Buenos Aires, 1610-1660", en Histórica, XXXIX.2, pp. 15-50.

Amadori, Arrigo (2020). “Agentes legos, saberes letrados y comunicación política: Buenos Aires, principios del siglo XVII", en Revista de Indias, Núm. 278, p. 63-99.

Bertrand, Michel y Andújar, Francisco (eds.) (2017). Gobernar y Reformar la Monarquía. Los agentes politicos y administrativos en España y América. Siglos XVIXIX. Valencia: Albatros.

Bahena Pérez, Martha Atzin (2020). “Negociar la ciudad. Procuradores de la gobernación de Guatemala en el Consejo de Indias, 1531-1540", en Nuevo Mundo Mundos Nuevos.

Birocco, Carlos María (2017). “¿Existieron en Buenos Aires los linajes de cabildantes? Procedencia y parentesco en la dirigencia concejil porteña (16051726)", en Rey Castelao, Ofelia y Cowen, Pablo, Familias en el Viejo y el Nuevo Mundo, Vol. 2 de la Col. Historia del Mundo Ibérico, pp. 311-340.

Birocco, Carlos María (2019). Testimonio del derecho que tienen los vecinos de Buenos Aires al ganado cimarrón de estas campañas (1704), Rosario: Prohistoria.

Brendecke, Arndt, y Mársico, Griselda (2012). Imperio e información: funciones del saber en el dominio colonial español. Madrid: Iberoamericana.

Bonialian, Mariano (2018). “Buenos Aires y la temprana globalización. Pensamiento y praxis de Martín Ignacio de Loyola, 1580-1605”, en Prohistoria, año XXI, núm. 30.

Cardim, Pedro (1999). “Amor e amizade na cultura política dos séculos XVI e XVII", en Lusitania sacra, pp. 21-57.

Domínguez Nafría, Juan Carlos (2001). “Carlos V y los orígenes de la polisinodia hispánica", en De la unión de coronas al Imperio de Carlos V, Madrid: 
Sociedad Estatal para la Conmemoración de los Centenarios de Felipe II y Carlos V, pp. 497-531.

Gaudin, Guillaume (2017). El imperio de papel de Juan Díez de la Calle: pensar y gobernar el Nuevo Mundo en el siglo XVII, Madrid: Fondo de Cultura Económica.

Guillaume Gaudin (2017b), “Un acercamiento a las figuras de agentes de negocios y procuradores de Indias en la Corte", en Nuevo Mundo Mundos Nuevos. [En línea] https://journals.openedition.org/nuevomundo/71390

Gaudin, Guillaume et al. (2017). “Vencer la distancia: Actores y prácticas del gobierno de los imperios español y portugués", en Nuevo Mundo Mundos Nuevos. [En línea] https://journals.openedition.org/nuevomundo/71453

Gaudin, Guillaume y Ponce Leiva, Pilar (2019). “El factor distancia en la flexibilidad y el cumplimiento de la normativa en la América Ibérica", en Les Cahiers de Framespa. Nouveaux champs de l'histoire sociale, núm. 30.

Gil Pujol, Xavier (2013). “Integrar un mundo. Dinámicas de agregación y de cohesión en la Monarquía de España”, en Mazín, Oscar y Ruiz Ibáñez, José Javier (eds.) Las Indias Occidentales: procesos de incorporación territorial a las monarquías ibéricas (siglos XVI a XVIII), México: El Colegio de México, pp. 69-108.

Infante, Lucas Antón (2019). El Consejo de Indias en la monarquía hispánica de Carlos II, 1665-1700, Tesis de doctorado defendida en la Universidad Complutense de Madrid.

Levillier, Roberto (1915). Correspondencia de la ciudad de Buenos Ayres con los reyes de España, Municipalidad de Buenos Aires, Tomo III.

López Nevot, José Antonio (2013). "Pedir y demandar, acusar y defender: los procuradores fiscales en las Audiencias y Chancillerías castellanas", en Anuario de historia del derecho español, Núm. 83, pp. 255-324.

Molina, Raúl (2000). Diccionario biográfico de Buenos Aires, 1580-1720, Buenos Aires: Academia Nacional de la Historia.

Ruiz Ibáñez, José Javier y Muñoz Rodríguez, Julio (2002). Sirviendo a la corte en la aldea, sirviendo a la aldea en la corte: veteranos, agentes y medios de relación en el siglo XVII castellano, en Bravo Lozano, Jesús (ed.) Espacios de poder: Cortes, Ciudades y Villas (s. XVI-XVII), Madrid: Universidad Autónoma de Madrid, 2002, vol. II, pp. 227-247.

Sanz Tapia, Ángel (2012) "La justicia en venta. El beneficio de cargos americanos de audiencia bajo Carlos II (1683-1700)", en Anuario de Estudios Americanos, Vol. 69-1, p. 63-90.

Storrs, Christopher (2003). "Pervivència de la monarquia espanyola sota el regnat de Carles II (1665-1700)", en Manuscrits: revista d'història moderna, Vol. 21, pp. 39-61. 
Suárez, Margarita (2001). Desafíos transatlánticos: mercaderes, banqueros y el estado en el Perú virreinal, 1600-1700, Lima: Fondo de Cultura Económica.

Trujillo, Oscar (2017). “Los Habsburgo en el Río de la Plata: Gobernadores de capa y espada en el Buenos Aires colonial temprano", en Anuario del Instituto de Historia Argentina, vol. 17, núm. 2. 